\title{
CONFLITOS NA ESCOLA: A IMPORTÂNCIA DA AMABILIDADE NA NEGOCIAÇÃO
}

\author{
Abílio Afonso Lourenço* \\ Maria Olímpia Almeida de Paiva**
}

\begin{abstract}
RESUMO
A negociação tem vindo a ser contemplada como uma das formas ideais de prática social. As diferenças respeitantes às características da Amabilidade, do Sexo e da Idade podem moldar selectivamente o fluxo do processo negocial. Neste estudo pretende-se determinar se a Amabilidade, bem como as variáveis sociodemográficas Sexo e Idade, são relevantes na explicação da Eficácia em Negociação. Como instrumentos utilizaram-se duas versões portuguesas, o CEN II para avaliar a Eficácia em Negociação e o NEO-PI-R para avaliar a Amabilidade. A amostra é constituída por 407 alunos do Ensino Secundário de uma escola do centro do Porto, Portugal. Dos resultados poder-se-á concluir que a Amabilidade $(\mathrm{p}<.001)$ e o Sexo $(\mathrm{p}<.01)$ são variáveis essenciais para o entendimento da eficácia condutual dos negociadores. Contudo, no que diz respeito à Idade, comprova-se não ser relevante na explicação da Eficácia Negocial. A presente investigação poderá contribuir para a problemática da perspectiva psicossocial sobre o conflito e a negociação.
\end{abstract}

PALAVRAS-CHAVE: Amabilidade. Conflito. Negociação.

\footnotetext{
* Doutor em Educação (Psicologia da Educação) pela Universidade do Minho (Braga) e professor da Escola Alexandre Herculano (Porto - Portugal). E-mail: aalourenco2402@clix.pt

** Doutora em Educação (Psicologia da Educação) pela Universidade do Minho (Braga) e professora da Escola Alexandre Herculano (Porto - Portugal). E-mail: mopaiva@clix.pt
} 


\begin{abstract}
Nowadays negotiation is taken as one of the ideal forms of social practice. The differences concerning Kindness, Sex and Age features can shape the flux of the negotiating process itself. This study aims at determining whether Kindness as well as socio-demographic variables Sex and Age, are relevant in the attempt to explain negotiation efficaciousness. We used two portuguese versions as instruments: CEN II to evaluate Effectiveness in Negotiation and NEO-PI-R to evaluate Kindness. The sample taken into account for that study is of 407 secondary school students of a school in Oporto, Portugal. Of the results it can be concluded that Kindness $(\mathrm{p}<.001)$ and Sex $(\mathrm{p}<.01)$ are essential variables for the understanding of the behavioural efficaciousness of those involved in the negotiating process. However Age hasn't been shown to be relevant for the explanation of the negotiation efficaciousness. This investigation can contribute to the problem of the psicossocial perspective about conflict and negotiation.
\end{abstract}

KEYWORDS: Kindness. Conflict. Negotiation.

\title{
Introdução
}

Actualmente, os mecanismos de negociação têm vindo a adoptar uma evidência central na gestão dos mais diversos conflitos que sucedem nos distintos níveis de realidade social (BAZERMAN \& NEALE, 1992). Na perspectiva de Serrano e Rodríguez (1993), essa situação decorre não só do próprio prestígio intrínseco à negociação, assim como das próprias potencialidades por ela abrangidas, designadamente na procura de soluções pertinentes e eficazes para as partes envolvidas em algum litígio. Smith e Ross (2007) referem que num estudo feito com pais que usavam procedimentos de mediação formais entre disputas de irmãos, estes adolescentes usavam estratégias de resolução de conflitos mais construtivas e chegavam a acordo mais frequentemente, obtendo-se, assim, ganhos sociais e social-cognitivos mais construtivos.

Sendo o conflito uma das transformações que ocorre no quotidiano escolar, e este ser influenciado por algumas variáveis sociodemográficas 
(LOURENÇO, 2003; PAIVA, 2003), é sobre o modo como negociar esse conflito que se desenvolveu este trabalho de investigação. Outra pesquisa de Lourenço e Paiva (2004b) evidencia, também, entre outros aspectos, a influência da Idade na eficácia condutual dos negociadores.

Deste modo, tendo como objectivo entender a forma de agir dos alunos quando confrontados com uma situação de negociação em contexto escolar, foi opção estudar a Eficácia em Negociação, tendo em conta algumas variáveis sociodemográficas (Sexo e Idade), bem como a Amabilidade como um dos factores da Personalidade.

Dos estudos de Cattell $(1943,1945)$ e Borgatta (1964) até McCrae e Costa (1987) chegou-se a um modelo de cinco factores ("Big Five") no qual pode ser encontrada a maior parte dos traços de personalidade, cujas dimensões fundamentais são a Abertura à Experiência, a Amabilidade, a Conscienciosidade, a Extroversão e o Neuroticismo (MCCRAE \& COSTA, 1992). O modelo em causa possibilita adquirir, a partir da delineação do posicionamento do sujeito nos cinco factores, um esquema compreensivo que agrupa características individuais que são motivacionais, experienciais, afectivas, atitudinais e interpessoais.

No presente estudo é abordado apenas o factor Amabilidade, com base na pesquisa de Barry e Friedman (1998), no qual os autores referem que este factor abrange facetas da personalidade que actuam nos processos e nos resultados negociais. Assim, a Amabilidade faz, por sua vez, uma avaliação constante da natureza da orientação interpessoal, que se movimenta entre a compaixão e a oposição nos pensamentos e atitudes.

Assim, Pruitt (1981) descreve o conflito como um facto no qual uma parte trata de actuar sobre a outra, ou sobre um elemento do ambiente comum, ao mesmo tempo que a outra parte oferece resistência. Mais recentemente, Serrano e Rodríguez (1993) estabelecem que o conflito será observável no momento em que duas ou mais partes se defrontam entre si, para atingir objectivos entendidos como inconciliáveis. Consequentemente a negociação de conflitos tem como finalidade solucioná-lo, de tal modo que a resolução se torne aceitável para ambas as partes envolvidas (SERRANO, 1996).

Para Bercovitch (citado por CUNHA, 2001), "a negociação representa um tipo de mecanismo de gestão do conflito, possuindo um 
mecanismo de decisão e um mecanismo de termo que podem mover as partes conflituosas de um estado de conflito para uma de não conflito" (p. 49). Será importante referir que nem sempre se torna possível solucionar um conflito por meio da negociação (KENNEDY, BENSON \& MCMILLAN, 1986), pois como destaca Rubin (1983), existem conflitos que não podem, e não devem, ser decididos através da negociação, defendendo este autor que a negociação continua a ser, contudo, uma das melhores opções para dissolver problemas.

Dos vários investigadores no âmbito da negociação, adoptaremos, particularmente, o modelo desenvolvido por Mastenbroek (1987, 1989), como linha orientadora da apresentação e interpretação das tácticas de negociação. A vantagem da aplicação deste modelo é que o mesmo é "[...] detentor de uma articulação conceptual consistente e de grande clareza entre as orientações de comportamento mais global e estratégico (as quatro dimensões da negociação eficaz, a que acresce uma quinta dimensão respeitante à negociação intra-organizacional) e as respectivas acções de que os negociadores dispõem para as pôr em prática (tácticas)" (CUNHA, 2001, p. 131).

O sentido das tácticas de negociação será norteado para as resoluções negociais de: obter resultados substanciais; influir no equilíbrio do poder; desenvolver um clima positivo; conseguir uma flexibilidade e influenciar os constituintes.

No entender de Cunha (2000), o modelo de Mastenbroek apresenta uma visão ampla sobre a eficácia em negociação, organizando-se, em especial, em torno das actividades problemáticas com que o negociador se defronta, assim como sobre as incertezas e medos que as mesmas the colocam. Esta visão está, nitidamente, em concordância com o plano de resolução de problemas e com o posicionamento estratégico de base, como fundamento primordial na firme flexibilidade, com vista à resolução clara do conflito.

Relativamente às várias definições de personalidade, estas detêm uma característica essencial: a personalidade é uma construção pessoal, que se verifica no decurso da vida. A personalidade não pode ser separada de aspectos pessoais, como a esfera emocional, intelectual, fisiológica, sociomoral, não existindo, também, livre da consciência e da representação 
de si, que cada um possui, nem da sua auto-estima. Rosenberg (citado por LOURENÇO \& PAIVA, 2004a) salienta que a "auto-estima é vista como a direcção da atitude (baixa ou alta) que o indivíduo possui para consigo mesmo" (p. 30). Entende-se, assim, por que motivo se atesta que a personalidade é um sistema dinâmico, uma elaboração contínua, que ocorre ao longo da vida do indivíduo.

Tendo presente esta teoria, a hipótese geral deste estudo consistiu em procurar determinar se o factor Amabilidade, assim como as variáveis sociodemográficas Sexo e Idade, são relevantes na explicação da Eficácia em Negociação. Mais propriamente, esta hipótese geral pode repartir-se por sete hipóteses específicas:

Hipótese 1 - Verifica-se um resultado estatisticamente significativo entre a Eficácia em Negociação e a Amabilidade;

Hipótese 1.1 - Observa-se um resultado com significância estatística entre a Eficácia em Negociação e a Confiança;

Hipótese 1.2 - Observa-se um resultado com significância estatística entre a Eficácia em Negociação e a Rectidão;

Hipótese 1.3 - Observa-se um resultado com significância estatística entre a Eficácia em Negociação e a Complacência;

Hipótese 1.4 - Observa-se um resultado com significância estatística entre a Eficácia em Negociação e a Sensibilidade;

Hipótese 2 - As pontuações obtidas na Eficácia em Negociação (CEN II) podem variar com o Sexo dos sujeitos;

Hipótese 3 - As pontuações alcançadas na Eficácia em Negociação (CEN II) podem variar com a Idade dos sujeitos.

\section{Metodologia}

Amostra

No estudo efectuado, a amostra é constituída por 407 alunos de uma escola secundária com $3 .^{\circ}$ ciclo do centro do Porto, que correspondem a $93,1 \%$ de um universo de 437 alunos que constituem a totalidade das turmas (42) do Ensino Secundário. Faltaram 30 (6,9\%) alunos no dia da aplicação do questionário. 
Da amostra, $156(38,3 \%)$ alunos pertencem ao sexo masculino e $251(61,7 \%)$ ao feminino, sendo $75(18,4 \%)$ do $10^{\circ}$ ano, $169(41,5 \%)$ do $11^{\circ}$ ano e $163(40,1 \%)$ do $12^{\circ}$ ano, distribuídos por 16,14 e 12 turmas, respectivamente. Apresentam, ainda, idades compreendidas entre os 17 e os 22 anos ( $\mathrm{M}=17,78 ; \mathrm{DP}=.99)$, cuja moda se situa nos 17 anos. Os indivíduos do sexo masculino exibem uma média de idades de 17,8 anos, enquanto os do sexo feminino expressam uma média de 17,7.

A população estudantil que frequenta esta escola é, na sua maioria, proveniente de bairros degradados, cujas famílias detêm condições de vida muito frágeis, bem como de classes sociais mais elevadas, o que dificulta a convivência entre os alunos devido às desigualdades sociais. Consequentemente, é possível presenciarem-se formas de comportamentos ofensivos, por parte dos adolescentes desta escola, assim como ocorrências pontuais de consumo de drogas.

A razão da escolha dos sujeitos desta amostra deveu-se ao facto de ser a população com que lidamos diariamente, a nível profissional, e ser um ciclo de estudos onde existe pouca investigação.

\section{Instrumento}

Utilizaram-se dois instrumentos, um para avaliar a Eficácia em Negociação e outro para a Amabilidade, como factor da personalidade. Relativamente ao primeiro (CEN - Cuestionario de Eficacia Negociadora), originalmente pensado e concebido, em 1989, por Serrano e Rodriguéz (c.f. RODRÍGUEZ, 1990), foi adaptado ao contexto português (CEN II) por Cunha $(1996,2000)$, sendo muito utilizado na avaliação do grau de eficácia negocial dos indivíduos, pois permite identificar, claramente, sujeitos muito eficazes e pouco eficazes em ambientes negociais. Assim, os indivíduos que alcançam as cotações mais altas na escala parecem ser os mais eficazes na negociação.

O CEN II é constituído por 42 itens, dos quais 10 estão assinalados em sentido inverso do propósito da eficácia negocial, e os outros 32 foram descritos em sentido positivo, em relação ao mesmo. Este instrumento tem por origem conceptual o modelo de negociação aconselhado por 
Mastenbroek (1987, 1989), tendo-se, também, tido em consideração as abordagens de outros autores, principalmente as de Bazerman e Neale (1993) e Pruitt e Carnevale (1993). A escala utilizada no CEN II é de formato Likert de cinco pontos, desde (1) "Discordo fortemente" até (5) "Concordo fortemente".

Para avaliar o factor Amabilidade foi utilizada a versão portuguesa do NEO-PI-R (Neuroticism, Extraversion, Openess-Personality Inventory - Revised), aferida por Lima (1997), originalmente desenvolvido por McCrae e Costa (1992) que operacionalizaram o modelo dos cinco factores. Deste modo, este instrumento baseia-se numa organização dos traços da personalidade, à volta de cinco dimensões gerais, estando apoiado em escalas de avaliação do comportamento, em resultados de questionários de personalidade e na analogia com outros sistemas de personalidade. Neste instrumento, o indivíduo tem a função de avaliar os itens que lhe são enunciados, numa escala de cinco pontos de formato Likert, graduada de (1) "Discordo fortemente" a (5) "Concordo fortemente". Cada uma das cinco dimensões está dividida em seis facetas diferentes e cada uma delas é constituída por oito itens.

A dimensão seleccionada para esta investigação empírica foi uma das usadas por Barry e Friedman (1998). As quatro facetas da dimensão Amabilidade são a Confiança, a Rectidão, a Complacência e a Sensibilidade, totalizando 32 itens.

Há que referir que foi opção incluir as facetas que se revelam mais apropriadas com base no marco teórico desenvolvido e nos objectivos que nos propusemos em termos de pesquisa. A aplicação do NEO-PI-R alarga-se por toda a idade adulta (a partir dos 17 anos) e a todos os graus de escolaridade e níveis de proveniências, bem como em contextos muito distintos.

\section{Procedimento}

A aplicação dos instrumentos foi feita em simultâneo a todos os alunos de cada turma e decorreu em Maio de 2006. O investigador esteve sempre presente, tendo fornecido todas as informações, de carácter geral, 
acerca da finalidade da investigação. Os alunos da amostra responderam voluntariamente a todas as questões, detectando-se que o tempo necessário variou entre 30 a 40 minutos. Foi assegurada a confidencialidade das respostas. O tratamento estatístico dos dados foi realizado com base no programa SPSS (versão 14.0) e os resultados foram analisados através da aplicação do Teste $\mathrm{t}$ para duas amostras independentes e da Correlação $\mathrm{R}$ de Pearson (Pestana \& Gageiro, 2000).

\section{Resultados}

De seguida, serão referidos e discutidos os itens com maior importância na explicação dos 5 factores: firme-flexibilidade procedimental; desenvolvimento de um clima construtivo; procurar influenciar o equilíbrio de poder; tentativa de obtenção de resultados substanciais; e estabelecimento de uma perspectiva racional de negociação.

No instrumento NEO-PI-R as pontuações obtidas ao nível das escalas das facetas permitem uma análise mais cuidada, pois possibilitam a medição dos traços específicos de cada domínio.

\section{Eficácia em Negociação}

O factor 1 é constituído por nove itens que fundamentam a quarta dimensão do modelo de conduta de negociação eficaz de Mastenbroek (1989), a qual se intitula "Firme-flexibilidade procedimental". Esta dimensão faz referência, especialmente, a uma flexibilidade procedimental, com a finalidade de escolher uma dinâmica flexível entre os negociadores. Apesar de o negociador apresentar uma posição de interesses fundamentada, a ideia passa, principalmente, pela vontade de se atingir um acordo, por meio de cedências e permutas recíprocas, nunca desprezando os interesses e os objectivos das partes envolvidas.

A partir das pontuações obtidas nos itens que compõem este factor, obteve-se uma média de 1 553,3, sendo, deste modo, o terceiro mais cotado. Estes nove itens correspondem a $21,4 \%$ do total dos itens da escala e representam $21,8 \%$ do total do score conseguido em todos os itens. Dos respondentes, $339(83,3 \%)$ procuram ser pessoas acessíveis mas 
simultaneamente firmes nos seus objectivos, enquanto 317 (77,9\%) estão atentos a alternativas para melhorar as iniciativas na negociação. Contudo, $58(14,3 \%)$ alunos não se preocupam em facultar a imagem de que são negociadores fiáveis e credíveis.

O factor 2 é composto por doze itens que consolidam a terceira dimensão do modelo de negociação de Mastenbroek (1989), denominado "Desenvolvimento de um clima construtivo". Os itens estão associados com o objectivo de desenvolver um clima construtivo, isto é, têm como base o desenvolvimento de um clima mais benéfico ao acto da negociação. Os negociadores procuram indicar alternativas que possibilitem a flexibilidade e exploração nas propostas, a partir da comunicação, tendo em consideração as metas e interesses da outra parte, evitando, desta forma, atitudes adversas e intimidatórios face ao adversário.

Assim, com base nas cotações dos itens que constituem este factor, constatou-se uma média de 1483,7 , sendo o quarto mais cotado. Estes doze itens equivalem a $28,6 \%$ do total dos itens da escala e representam $27,7 \%$ do total do score alcançado em todos os itens. Dos sujeitos inquiridos, $315(77,4 \%)$ tentam ter uma certa flexibilidade nos meios para alcançar o acordo, sem fugir, todavia, dos seus próprios objectivos, enquanto que 306 (75,2\%) consideram que é conveniente criar segurança na outra parte, se se quer obter um acordo satisfatório, por um longo período. Por seu lado, $56(13,8 \%)$, concebem que, para se alcançar o acordo, não é muito útil expressar gostos comuns, nem sublinhar as semelhanças com o oponente.

$\mathrm{O}$ factor 3 é formado por nove itens que descrevem uma dimensão de procura de influência quanto ao equilíbrio de poder entre as partes, expressando a complexidade do segundo tipo de condutas indicadas no modelo de eficácia negocial de Mastenbroek (1989). Este modelo destaca ser indispensável uma certa estabilidade de domínio entre as partes, com uma adequada e superior capacidade e espaço de manobra para que o negociador consiga o acordo eficaz.

Sendo o factor menos cotado, com uma média de 1 476,2, estes nove itens correspondem a $21,4 \%$ do total dos itens da escala e justificam $20,7 \%$ do total do score conseguido em todos os itens. Dos alunos da amostra, 360 (88,5\%) não fazem ameaças inequívocas, nem demonstram que as suas decisões são irreversíveis e $266(65,4 \%)$ consideram que a frase 
"O que é bom para a outra parte é mau para mim" nem sempre corresponde à verdade. Contudo, $116(28,5 \%)$ aludem a que o bom negociador deve procurar a derrota do seu oponente.

O factor 4 é constituído por sete itens que estão em concordância com o primeiro tipo de condutas complexas que se destacam no processo negocial de Mastenbroek (1989) e que se denomina "Tentativa de obtenção de resultados substanciais". A obtenção de resultados substanciais identifica-se como sendo o objectivo primordial da negociação, onde a principal finalidade é obter bons resultados, o que vai nortear todas as demais acções.

É o segundo factor mais valorizado, com uma média de 1 588,6. Estes itens dizem respeito a $16,7 \%$ do total que compõe a escala e justificam $17,3 \%$ do total do score conseguido em todos os itens. Dos sujeitos em estudo, $363(89,2 \%)$ promovem a comunicação aberta revelando honestamente as informações necessárias ao acordo mútuo, enquanto 346 (85\%) defendem que é muito importante analisar os interesses subjacentes de ambas as partes, para se conseguir alcançar o acordo. Porém, 64 (15,7\%) consideram que quando têm de advertir os seus oponentes sobre algo, o fazem de modo irritado ou sarcástico.

O factor 5 é constituído por cinco itens e revela-se pelo estabelecimento de uma abordagem racional de negociação. Apontam uma dimensão que se inclui na perspectiva defendida por Bazerman e Neale (1993), onde se aconselha uma racionalidade superior por parte do negociador, com o objectivo de evitar, deste modo, a racionalidade decisional fincada em propensões distorcidas face ao opositor, o que complicaria a realização de acordos de maior eficácia (Cunha, 2000).

Este factor estaria de acordo com a primeira dimensão do modelo de Mastenbroek (1989), conhecida pela "Tentativa de obtenção de resultados substanciais", onde a obtenção de resultados abrangerá, também, uma análise aos objectivos comuns entre as partes, com o fim de se conseguir um acordo lícito e admissível para ambas.

Sendo o factor com o score mais elevado, obteve uma média de 1608,4 . Estes itens correspondem a $11,9 \%$ do total dos itens da escala e justificam $12,5 \%$ do total do score conseguido em todos os itens. Dos sujeitos inquiridos, $354(87,0 \%)$ escutam atentamente a outra parte de modo 
a se certificarem da possibilidade de articular interesses entre as partes e $349(85,7 \%)$ procuram sempre novas soluções para o problema de maneira a chegar ao acordo. No entanto, 31 (7,6\%) alunos não se preocupam em saber quais os custos e riscos que as propostas que fazem colocam à outra parte.

Outro facto que merece ainda a atenção é que $165(40,5 \%)$ alunos manifestam como sendo "Indiferente", na negociação, o ser importante conceder a pouco e pouco, com o objectivo de criar reciprocidade na outra parte. Também, $144(35,4 \%)$ alunos consideram "Indiferente" o facto de ser muito útil solicitar um descanso, para discutir os assuntos num ambiente menos formal, quando se atinge o "ponto-morto" na negociação.

\section{Eficácia em Negociação em função da Amabilidade}

Como preconizam Greenhalgh, Neslin e Gilkey (1985), "reconhecese que as personalidades dos negociadores têm importantes efeitos sobre as negociações; [...]. Rubin e Brown (1975) assinalam que são as predisposições de personalidade mais amplas, e não os traços de personalidade isolados, os que afectam a negociação na vida real" (p. 9).

$\mathrm{Na}$ interpretação das condições que compreendem os efeitos da personalidade na negociação, Barry e Friedman (1998) referem que esses efeitos nos processos e resultados negociais podem ser diminuídos pelas aspirações elevadas. Uma grande motivação para o sucesso poderá levar a uma forma de actuar que seja contraditória com a personalidade daquele que negoceia e, na ausência de tal motivação, a actuação do negociador poderá ser mais afectada pelas suas características estáveis de personalidade.

Analisando o factor Amabilidade seleccionado para o estudo (c.f. QUADRO 1), pode constatar-se que existe uma relação estatisticamente significativa. Este factor apresenta uma associação linear positiva e moderada $(\mathrm{r}=.446 ; \mathrm{p}<.001)$. 


\section{QUADRO 1 \\ Correlação R de Pearson para a Eficácia em Negociação em função da Amabilidade}

\begin{tabular}{ccc}
\hline \multirow{2}{*}{ Eficácia em Negociação } & \multicolumn{2}{c}{ Amabilidade } \\
\cline { 2 - 3 } & $\mathrm{r}$ & $p$ \\
\cline { 2 - 3 } & * Correlação significativa com $\mathrm{p}<.001$ & $\mathbf{. 0 0 0}$ \\
\hline
\end{tabular}

De acordo com os resultados do quadro 1, é de aceitar a hipótese 1 atrás formulada, onde se procurava determinar se o factor Amabilidade era relevante na explicação da eficácia comportamental dos negociadores.

Desta forma, a Amabilidade pode denunciar um carácter pró-social estável, em vez de evidenciar, simplesmente, um interesse individual próprio, em situações que englobam interdependência. Também De Dreu e Van Lange (1995) referem que um menor número de requisitos, e um maior número de cedências, era realizado pelos negociadores com uma orientação pró-social, em oposição àqueles que tinham uma orientação social mais competitiva e individualista.

Quanto à correlação entre a Eficácia em Negociação e as facetas da Amabilidade (c.f. Quadro 2) verifica-se uma associação linear positiva fraca em todas as suas facetas, sendo as correlações estatisticamente significativas.

$\mathrm{Na}$ "Confiança" ( $\mathrm{r}=.229 ; \mathrm{p}=<.001)$, tendo-se obtido uma pontuação ligeiramente acima da média, os indivíduos da amostra caracterizam-se por tenderem a atribuir intenções bondosas aos outros e a considerá-los sérios e bem-intencionados. Esta faceta é encarada como uma das variáveis de referência da Psicologia, considerada por Erikson (c.f. COSTA \& MCCRAE, 1992) como a base do desenvolvimento psicossocial.

$\mathrm{Na}$ faceta "Rectidão" $(\mathrm{r}=.360 ; \mathrm{p}=<.001)$ tendo-se obtido uma pontuação um pouco acima da média, permite-nos admitir que os alunos são francos, sinceros, frontais e naturais ao lidar com os outros.

Relativamente à "Complacência" $(\mathrm{r}=.287 ; \mathrm{p}=<.001)$ obteve-se, também, uma pontuação que nos leva a dizer que os alunos são capazes de aceitar a opinião dos outros, são brandos, inibem a agressividade, esquecem e perdoam. 
Quanto à faceta "Sensibilidade" $(\mathrm{r}=.395 ; \mathrm{p}=<.001)$, em função da pontuação obtida, revela que os sujeitos são, tendencialmente, guiados pelos sentimentos, particularmente os de simpatia, ao ajuizarem e tomarem atitudes. Assim sendo, são de aceitar as hipóteses 1.1, 1.2, 1.3 e 1.4.

\section{QUADRO 2}

Correlação R de Pearson para a Eficácia em Negociação em função das facetas da Amabilidade

\begin{tabular}{|c|c|c|c|c|c|c|}
\hline & & & \multicolumn{4}{|c|}{ Amabilidade } \\
\hline & & & Confiança & Rectidão & Complacência & Sensibilidade \\
\hline Eficácia & em & $\mathrm{r}$ & $.229 *$ & $.360 *$ & $.287 *$ & $.395^{*}$ \\
\hline Negociação & & $p$ & .000 & .000 & .000 & .000 \\
\hline
\end{tabular}

Analisando a correlação entre os diferentes factores da Eficácia em Negociação com a Amabilidade (c.f. Quadro 3), verifica-se que as associações são todas estatisticamente significativas, onde o factor 3 "Procurar influenciar o equilíbrio de poder" apresenta uma associação positiva moderada $(r=.498 ; \mathrm{p}=<.01)$. O factor 2 - "Desenvolvimento de um clima construtivo" ( $r=.326 ; p=<.01)$, o factor 4 - "Tentativa de obtenção de resultados substanciais" $(\mathrm{r}=.318 ; \mathrm{p}=<.01)$ e o factor 5 - "Procurar influenciar o equilíbrio de poder" $(\mathrm{r}=.363 ; \mathrm{p}=<.01)$ apresentam correlações positivas fracas e no factor 1 - "Firme-flexibilidade procedimental" constata-se uma associação positiva muito fraca $(\mathrm{r}=.165 ; \mathrm{p}=<.01)$.

\section{QUADRO 3}

\section{Correlação R de Pearson para os diferentes factores da Eficácia em} Negociação em função da Amabilidade

\begin{tabular}{cccc}
\hline & & \multicolumn{2}{c}{ Amabilidade } \\
\cline { 3 - 4 } & Factor 1 & $.165^{* *}$ & $\mathbf{. 0 0 1}$ \\
Eficácia em Negociação & Factor 2 & $.326^{*}$ & $\mathbf{. 0 0 0}$ \\
& Factor 3 & $.498^{*}$ & $\mathbf{. 0 0 0}$ \\
& Factor 4 & $.318^{*}$ & $\mathbf{. 0 0 0}$ \\
& Factor 5 & $.363^{*}$ & $\mathbf{. 0 0 0}$ \\
\hline * Correlação significativa com $\mathrm{p}<.001$ & \\
** Correlação significativa com $\mathrm{p}<.01$ &
\end{tabular}


Da análise dos resultados poder-se-á dizer que os indivíduos altruístas, bondosos, fiáveis e prestáveis, detentores de amabilidade, além das capacidades atrás descritas, procuram influenciar o equilíbrio de poder entre as partes. Este é fundamental para uma determinada estabilidade de domínio entre os negociadores, com uma ajustada e superior capacidade e espaço de manobra para que o negociador obtenha o acordo eficaz.

Variáveis sociodemográficas

No presente estudo, o objectivo consiste em identificar diferenças estatisticamente significativas, partindo das pontuações obtidas pelos alunos no CEN II. Assim, optámos por aplicar o Teste t para duas amostras independentes e o $\mathrm{R}$ de Pearson aquando do estudo das variáveis independentes Sexo e Idade, respectivamente, usando como variável dependente a Eficácia em Negociação.

Eficácia em Negociação em função do Sexo

Quanto a esta variável, foi formulada a hipótese de que as pontuações obtidas no CEN II poderiam variar com o Sexo dos indivíduos. Da análise da figura 1 é possível constatar que existe um aumento da média da Eficácia em Negociação quando se passa do sexo masculino para o feminino.

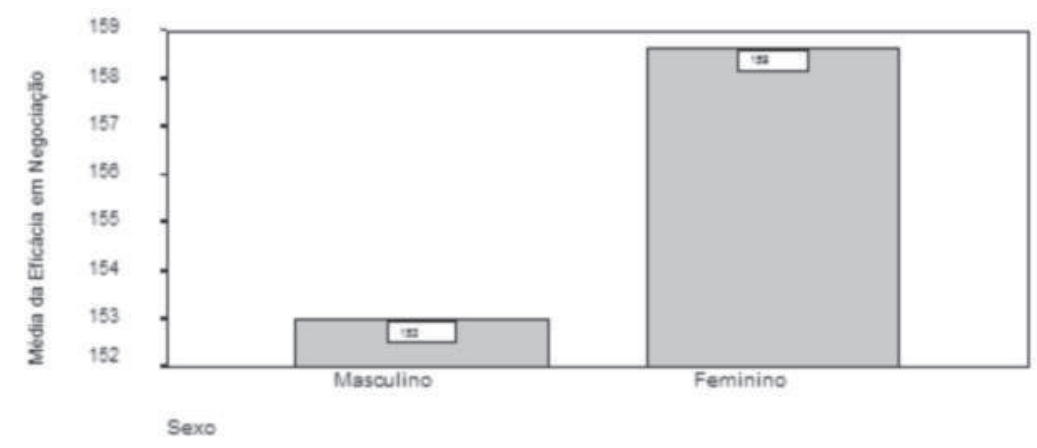

FIGURA 1 - Tendência da Eficácia em Negociação em função do Sexo 
Conforme se verifica no quadro 4 , o Teste $t$ aplicado comprova, nitidamente, a não rejeição da hipótese $2(\mathrm{t}=-3,217$; $\mathrm{gl}=285,2 ; \mathrm{p}<.01)$, uma vez que se verificaram diferenças assinaláveis nas médias entre os elementos masculinos $(\mathrm{M}=152,98 ; \mathrm{DP}=18,38)$ e femininos $(\mathrm{M}=158,65 ; \mathrm{DP}=15,35)$ da amostra, isto é, verificam-se diferenças estatisticamente significativas.

\section{QUADRO 4}

Teste t para a variável Eficácia em Negociação em função do Sexo

\begin{tabular}{|c|c|c|c|c|c|c|}
\hline \multirow{4}{*}{$\begin{array}{l}\text { Eficácia em } \\
\text { Negociação }\end{array}$} & \multirow[b]{3}{*}{$\begin{array}{l}\text { Igualdade de variân- } \\
\text { cias assumida }\end{array}$} & \multicolumn{2}{|c|}{$\begin{array}{l}\text { Teste de Levene } \\
\text { para igualdade de } \\
\text { variâncias }\end{array}$} & \multicolumn{3}{|c|}{$\begin{array}{l}\text { Teste t para igualdade de } \\
\text { médias }\end{array}$} \\
\hline & & $\mathrm{F}$ & sig. & $\mathrm{t}$ & $\mathrm{gl}$ & $p$ \\
\hline & & 8,539 & .004 & $-3,354$ & 405 & .001 \\
\hline & $\begin{array}{l}\text { Igualdade de variân- } \\
\text { cias não assumida }\end{array}$ & & & $-3,217$ & 285,2 & .001 \\
\hline
\end{tabular}

Ao considerarmos a estrutura factorial do instrumento CEN II e analisando o quadro 5, verifica-se que as diferenças que existem nas médias da Eficácia em Negociação em função do Sexo, no factor 2 "Desenvolvimento de um clima construtivo" ( $\mathrm{t}=-2,182 ; \mathrm{gl}=286,4 ; \mathrm{p}<.05)$ e no factor 3 - "Procurar influenciar o equilíbrio de poder" $(\mathrm{t}=-5,796$; $\mathrm{gl}=405 ; \mathrm{p}<.001)$, são estatisticamente significativas.

\section{QUADRO 5}

Teste t para os factores da Eficácia em Negociação em função do Sexo

\begin{tabular}{|c|c|c|c|c|c|c|c|c|c|}
\hline & & Sexo & Média & DP & $\mathrm{F}$ & sig. & $\mathrm{t}$ & $\mathrm{gl}$ & $p$ \\
\hline \multirow{5}{*}{$\begin{array}{l}\text { Eficácia em } \\
\text { Negociação }\end{array}$} & Factor 1 & $\begin{array}{l}\text { masc. } \\
\text { fem. }\end{array}$ & $\begin{array}{l}34,35 \\
34,35\end{array}$ & $\begin{array}{l}5,23 \\
4,64\end{array}$ & 2,049 & .153 & .012 & 405 & (n. s.) \\
\hline & Factor 2 & $\begin{array}{l}\text { masc. } \\
\text { fem. }\end{array}$ & $\begin{array}{l}42,92 \\
44,26\end{array}$ & $\begin{array}{l}6,41 \\
5,38\end{array}$ & 4,268 & .039 & $-2,182$ & 286,4 & .030 \\
\hline & Factor 3 & $\begin{array}{l}\text { masc. } \\
\text { fem. }\end{array}$ & $\begin{array}{l}30,57 \\
33,93\end{array}$ & $\begin{array}{l}6,00 \\
5,49\end{array}$ & 3,448 & .064 & $-5,796$ & 405 & .000 \\
\hline & Factor 4 & $\begin{array}{l}\text { masc. } \\
\text { fem. }\end{array}$ & $\begin{array}{l}26,97 \\
27,54\end{array}$ & $\begin{array}{l}3,48 \\
3,29\end{array}$ & .428 & .513 & $-1,642$ & 405 & (n. s.) \\
\hline & Factor 5 & $\begin{array}{l}\text { masc. } \\
\text { fem. }\end{array}$ & $\begin{array}{l}19,54 \\
19,89\end{array}$ & $\begin{array}{l}2,74 \\
2,35\end{array}$ & 5,568 & .019 & $-1,311$ & 291,2 & (n. s.) \\
\hline
\end{tabular}


Os itens onde o sexo masculino respondeu em maior número, no sentido positivo, são: "Faço ameaças inequívocas, demonstrando que as minhas decisões são irreversíveis" (82,7\%); "Procuro sempre novas soluções para o problema, de maneira a chegar ao acordo" (82,1\%); e "Demonstro interesse no bem-estar do meu oponente e vontade de encontrar soluções harmoniosas" (82,1\%). Relativamente ao sexo feminino os itens foram: "Promovo a comunicação aberta, revelando honestamente as informações necessárias ao acordo mútuo" (93,6\%); "Faço ameaças inequívocas, demonstrando que as minhas decisões são irreversíveis" (92,0\%); e "É muito importante analisar os interesses subjacentes de ambas as partes para se conseguir alcançar o acordo" (89,6\%).

Relativamente à percepção da situação de conflito, os rapazes, geralmente, estão mais voltados para a maximização de resultados, enquanto as raparigas se preocupam mais com a manutenção da relação. Verificase que, segundo Gilkey e Greenhalgh (citado por Cunha, 2001), quanto à percepção sobre o opositor, "os homens tendem a percepcioná-lo como sendo fundamentalmente distinto de si próprios e as mulheres tendem a ser mais empáticas e percepcioná-lo como semelhantes a si mesmas" (p. 210). Outro facto que merece a atenção é que o sexo feminino obteve uma cotação superior em todos os factores, bem como em todos os itens que os constituem, o que nos poderá confirmar, neste estudo, uma maior eficácia negocial (c.f. FIG. 1).

\section{Eficácia em Negociação em função da Idade}

Analisando a figura 2 verifica-se que há uma ligeira flutuação da Eficácia em Negociação entre os 17 e os 20 anos, observando-se, a partir desta idade, um incremento acentuado.

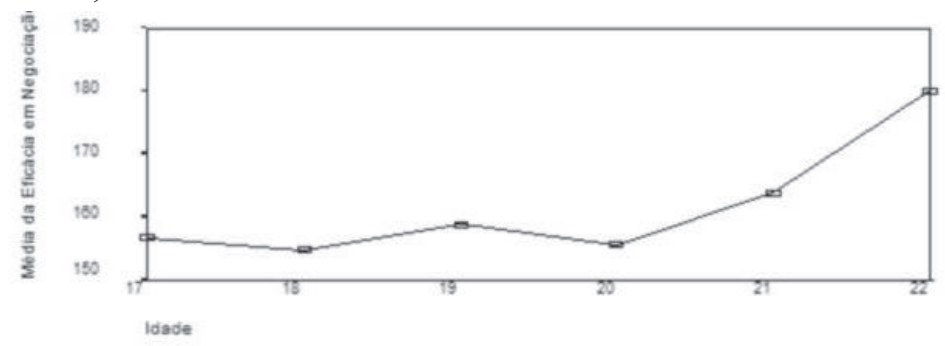

FIGURA 2 - Tendência da Eficácia em Negociação em função da Idade 
Em termos descritivos e da análise dos resultados obtidos da Correlação R de Pearson (c.f. Quadro 6), poder-se-á dizer que a muito fraca associação linear $(\mathrm{r}=.034)$ existente entre a Idade dos alunos e a Eficácia em Negociação não é estatisticamente significativa.

\section{QUADRO 6}

Correlação R de Pearson para a variável Eficácia em Negociação em função da Idade

\begin{tabular}{lcc}
\hline & & Idade \\
\hline Eficácia em Negociação & Correlação de Pearson & .034 \\
& sig. & .496 \\
\hline
\end{tabular}

Quanto aos factores da Eficácia em Negociação em função da Idade, observa-se uma muito fraca associação linear em todos eles não sendo esta, também, estatisticamente significativa (c.f. QUADRO 7).

QUADRO 7

Correlação R de Pearson para os diferentes factores em função da Idade

\begin{tabular}{llcc}
\hline \multirow{2}{*}{ Eficácia em Negociação } & & \multicolumn{2}{c}{ Idade } \\
\cline { 2 - 4 } & & $\mathrm{r}$ & $\mathrm{p}$ \\
\cline { 2 - 4 } & Factor 1 & .007 & (n. s.) \\
& Factor 2 & .009 & (n. s.) \\
& Factor 3 & .015 & (n. s.) \\
& Factor 4 & .033 & (n. s.) \\
& Factor 5 & .039 & (n. s.) \\
\hline
\end{tabular}

Relativamente a esta variável, partiu-se da hipótese de que as pontuações obtidas no CEN II poderiam variar com a Idade do indivíduo. A Correlação R de Pearson empreendida comprova que a variável Idade não se pode encontrar na base das diferenças significativas no que concerne às pontuações do CEN II. Permite-nos concluir, assim, que a hipótese 3 apresentada sobre a variável sociodemográfica em exame deverá ser refutada, já que os sujeitos dos diferentes níveis etários apresentaram, no instrumento 
em estudo, cotações médias muito próximas.

Como refere Cunha (2000), é de salientar que os resultados obtidos não são uma garantia de uma actuação conforme o que responderam, pois os alunos são questionados quanto aos comportamentos adoptados perante um conflito e não se verificam in loco as atitudes no momento real da situação conflitual.

\section{Discussão}

Devido à relevância concedida à negociação construtiva e eficaz dos conflitos, e dado que é uma problemática relativamente pouco investigada, foi opção avaliar uma pequena amostra, de forma a identificar as atitudes mais usuais mediante uma situação de conflito interpessoal em espaço escolar.

Dando resposta às hipóteses anteriormente formuladas, apresentamse as conclusões obtidas da análise dos resultados.

Analisando o factor Amabilidade verificou-se que a associação com a Eficácia em Negociação é linear e moderada. Constatou-se, também, que pertencer ao sexo masculino ou feminino influencia de uma forma significativa a Eficácia em Negociação.

As respectivas médias em função do Sexo foram estatisticamente significativas para o factor 2, - "Desenvolvimento de um clima construtivo", onde os indivíduos do sexo feminino apresentam uma pontuação média ligeiramente mais elevada e, por isso, poder-se-á admitir que tendencialmente criam uma certa facilidade de comunicação entre as partes e estabelecem relações interpessoais isentas de crispação.

Para o factor 3 - "Procurar influenciar o equilíbrio de poder" os sujeitos do sexo feminino apresentam uma pontuação média mais elevada. Os itens que constituem este factor levam-nos a crer que os negociadores da amostra apostam, especialmente, na prática de estratégias de menor dureza com o objectivo de se obter um equilíbrio na sua relação com o oponente, ou seja, os comportamentos eleitos pelos negociadores sugerem ser aqueles que estão mais em acordo com a resolução de problemas, com a finalidade de se desenvolver uma determinada margem de manobra de negociação.

Educ. e Filos. Uberlândia, v. 23, n. 46, p. 145-168, jul./dez. 2009. 
Relativamente à comparação das médias da Eficácia em Negociação em função da Idade, é de referir as diferenças não significativas, destacandose o facto de haver uma ligeira flutuação da Eficácia em Negociação entre os 17 e os 20 anos, sendo possível observar, a partir desta idade, um incremento acentuado. Se tomarmos em consideração os diferentes factores da escala CEN II, também se verifica que a média da Eficácia em Negociação não é significativamente diferente em todos os seus factores.

Concluindo, a eficácia negocial passará, consequentemente, pela organização do ambiente de aprendizagem que deverá ser estimulador, de forma a suscitar o interesse e a participação dos alunos, incentivando o seu adequado desenvolvimento global e de autonomia. A doutrina inerente ao estudo do conflito e da negociação assume, assim, cada vez mais, uma importância primordial, pois significa ir estabelecendo os fundamentos de outros aspectos cruciais - as soluções para uma educação mais ajustada para enfrentar os conflitos e os princípios orientadores para a formação na prática da negociação.

A Escola é um lugar onde diariamente convivem pessoas com diferentes características, educações, religiões e personalidades. Entre tantas diferenças é natural que surjam divergências das mais diversas espécies. É imprescindível, então, a boa administração dos problemas que venham a surgir para que a harmonia e o respeito estejam presentes no ambiente escolar e não interfiram no processo de ensino-aprendizagem. Nesse contexto, surge a mediação para tentar solucionar e também prevenir quaisquer conflitos que se desenvolvam na instituição de ensino (SALES \& ALENCAR, 2004). A mediação é uma ferramenta que pode ser associada à resolução construtiva de conflitos, em especial numa organização onde os seus intervenientes encontram as suas diferenças (GALANO, 1999; SALES 2004, 2005; SELIGMAN, 2004). Battaglia (citada por SALES, 2007), por sua vez argumenta que, "considerando a escola como instituição que objectiva a educação cultural e social do homem, a mediação escolar se coloca como um convite à aprendizagem e ao aperfeiçoamento da habilidade de cada um na negociação e na resolução de conflito, baseada no modelo 'ganha-ganha', onde todas as partes envolvidas na questão saem vitoriosas e são contempladas nas resoluções tomadas" (p. 132).

A conceptualização de uma negociação dinâmica e eficaz tem as

Educ. e Filos. Uberlândia, v. 23, n. 46, p. 145-168, jul./dez. 2009. 
limitações intrínsecas a praticamente todos os modelos. Trata-se, assim, de uma perspectiva ampla e estruturada sobre as actividades difíceis e complexas com que o negociador se depara. Esta perspectiva vai de encontro ao nosso próprio ponto de vista, ou seja, à estratégia da resolução de problemas como posicionamento estratégico basilar, com fundamento essencial na firme-flexibilidade, para a solução construtiva do conflito.

\section{Referências}

Barry, B., \& Friedman, R. A. (1998). Bargainer characteristics in distributive and integrative negotiation. Journal of Personality and Social Psychology, 74 (2), 345-349.

Bazerman, M. H., \& Neale, M. A. (1992). Negotiating rationally. New York: The Free Press.

Bazerman, M. H., \& Neale, M. A. (1993). La negociación racional - en un mundo irracional. Barcelona: Paidós.

Borgatta, E. F. (1964). The structure of personality characteristics. Behavioral Science, 61 (1), 8-17.

Cattell, R. B. (1943). The description of personality: Basic traits resolved into clusters. Journal Abnormal and Social Psychology, 38 (1), 476-506.

Cattell, R. B. (1945). The description of personality: Principles and findings in a factor analysis. American Journal of Psychology, 58 (1), 69-90.

Costa, P. T., \& McCrae, R. R. (1992). The five-factor model of personality and its relevance to personality disorders. Journal of Personality Disorders, 6 (4), 343-359.

Cunha, P. (1996). Análise empírica sobre a eficácia negociadora. Trabalho de investigação prévio à tese doutoral, Universidade de Santiago de Compostela, Santiago de Compostela .

Cunha, P. (2000). Estratégias e tácticas em negociação: para um modelo de eficácia negocial. Tese de doutoramento. Santiago de Compostela: Universidade Santiago de Compostela.

Cunha, P. (2001). Conflito e negociação. Porto: ASA Editores. 
De Dreu, C. K. W., \& Van Langer, P. A. M. (1995). The impact of social value orientations on negotiator cognition and behavior. Personality and Social Psychology Bulletin, 21 (1), 1178-1188.

Galano, M. H. (1999). Mediação - uma nova mentalidade. In A. Oliveira (coord.), Mediação - métodos de resolução de controvérsias (pp. 102112). S. Paulo: LTr.

Greenhalgh, L., Neslin, S. A., \& Gilkey, R. W. (1985). The effects of negotiator preferences, situational power, and negotiator personality on outcomes of business negotiation. Academy of Management Journal, 28 (1), 9-23.

Kennedy, G., Benson, J., \& McMillan, J. (1986). Cómo negociar com éxito. Bilbao: Deusto.

Lima, M. P. (1997). Ocean ou iceberg: inventário de personalidade NEO$P I-R$. Tese de doutoramento. Coimbra: Faculdade de Psicologia e Ciências da Educação da Universidade de Coimbra.

Lourenço, A. A. (2003). Indisciplina na escola: uma abordagem comportamental e causal. Tese de mestrado. Porto: Faculdade de Ciências Humanas e Sociais da Universidade Fernando Pessoa.

Lourenço, A. A., \& Paiva, M. O. A. (2004a). Disrupção escolar - estudo de casos. Porto: Porto Editora.

Lourenço, A. A., \& Paiva, M. O. A. (2004b). Negociação de conflitos em contexto escolar. Revista de Psicologia, Educação e Cultura, 8 (1), 121140.

Mastenbroek, W. (1987). Conflict management and organization development. New York: Wiley.

Mastenbroek, W. (1989). Negotiate. Oxford, England: Basil Blackwell.

McCrae, R. R., \& Costa, E. T. (1985). Comparison of EPI and psychoticism scales with measures of the five-factor model of personality. Personality and Individual Differences, 6 (1), 587-597.

McCrae, R. R., \& Costa, P. T. (1987). Validation of the five-factor model of personality across instruments and observers. Journal of Personality and Social Psychology, 52 (1), 81-90. 
McCrae, R. R., \& Costa, P. T. (1992). Discriminant validity of NEO-PIR facet scales. Educational and Psychological Measurement, 52 (1), 229237.

Paiva, M. O. A. (2003). Comportamentos disruptivos dos adolescentes na escola: influências do autoconceito, sexo, idade e repetência. Tese de mestrado. Porto: Faculdade de Ciências Humanas e Sociais da Universidade Fernando Pessoa.

Pestana, M. H., \& Gageiro, J. N. (2000). Análise de dados para ciências sociais - a complementaridade do SPSS (2 $2^{\mathrm{a}}$ ed.). Lisboa: Edições Sílabo. Pruitt, D. G. (1981). Negotiation behavior. New York: Academic Press.

Pruitt, D. G., \& Carnevale, P. J. (1993). Negotiation in social conflict. Burkingham: Open University Press.

Rodríguez, M. D. (1990). Analisis de las caracteristicas psicométricas y estructura factorial del cuestionario de eficacia en la negociación, CEN. Libro de Simposios del III Congreso Nacional de Psicología Social. Santiago de Compostela.

Rubin, J. Z. (1983). Negotiation: an introduction to some issues and themes. American Behavioral Scientist, 27 (2), 135-147.

Sales, L. M. M. (2004). Justiça e mediação de conflitos. Belo Horizonte: Del Rey.

Sales, L. M. M. (2005). Mediare: Um guia prático para mediadores. Fortaleza: Universidade de Fortaleza.

Sales, L. M. M. (2007). A escola na actualidade e a mediação escolar. Pensar, Fortaleza, edição especial, 122-135.

Sales, L. M. M., \& Alencar, E. C. O. (2004). Mediação de conflitos escolares - uma proposta para a construção de uma nova mentalidade nas escolas. Pensar, Fortaleza, 9 (9), 89-96.

Seligman, M. E. P. (2004). Felicidade Autêntica: usando a nova psicologia positiva para a realização permanente. Rio de Janeiro: Objetiva.

Serrano, G. (1996). Elogio de la negociación. Discurso inaugural lido en la solemne apertura do curso académico 1996-97, Santiago de Compostela, Universidad de Santiago de Compostela.

Educ. e Filos. Uberlândia, v. 23, n. 46, p. 145-168, jul./dez. 2009. 
Serrano, G., \& Rodríguez, M. D. (1993). Negociación en las organizaciones. Madrid: Eudema.

Smith, J., \& Ross, H. (2007). Training Parents to Mediate Sibling Disputes Affects Children's Negotiation and Conflict Understanding. Child Development, 78 (3), 790-805.

Data de registro: $14 / 08 / 08$

Data de aceite: 17/10/08 


\section{crítica \\ REVISTA HISPANOAMERICANA DE FILOSOFÍA}

\section{Artículos}

JOSÉ TOMÁS ALVARADO MARAMBIO

Bidimensionalismo epistémico y el espacio ontológico modal

MANUEL PÉREZ OTERO

An Evaluation of Kripke's Account of the Illusion of Contingency

$$
\text { ANDREA IACONA }
$$

Future Contingents and Aristotle's Fantasy

MATTHEW E. MOORE

The Completeness of the Real Line

Notas bibliográficas

CARLOS J. MOYA, Moral Responsibility. The Ways of Scepticism [Carlos Thiebaut]

JOHN MARTIN FISCHER, ROBERT KANE, DERK PEREBOOM Y MANUEL VARGAS,

Four Views on Free Will

[Carlos G. Patarroyo G.]

Libros recibidos

Vol. 39 / No. 117 / diciembre 2007/ ISSN 0011-1503

Crítica, Revista Hispanoamericana de Filosofía aparece tres veces al año en

los meses de abril, agosto y diciembre. Es una publicación del Instituto

de Investigaciones Filosóficas (UNAM). Todo tipo de correspondencia

deberá ser dirigida al Apartado Postal 70-447, Coyoacán, 04510,

México, D.F. Correo electrónico: critica@filosoficas.unam.mx.

Versión electrónica: http://critica.filosoficas.unam.mx 